\title{
A MULHER COMO VÍTIMA DE VIOLÊNCIA DOMÉSTICA
}

\author{
THE WOMAN AS VICTIM OF VIOLENCE \\ LA MUJER COMO VÍCTIMA DE LA VIOLENCIA DOMESTICA
}

\author{
Mirian Botelho Sagim* \\ Zélia Maria Mendes Biasoli-Alves** \\ Vanessa Delfino*** \\ Fabiola Petri Venturini***
}

* Doutoranda do Programa de Pós-Graduação em Psicologia do Departamento de Psicologia e Educação da Faculdade de Filosofia, Ciências e Letras de Ribeirão Preto da Universidade de São Paulo (USP).

** Professora Titular do Departamento de Psicologia e Educação da Faculdade de Filosofia, Ciências e Letras de Ribeirão Preto da USP

*** Doutorandas do Programa de Pós-Graduação em Psicologia do Departamento de Psicologia e Educação da Faculdade de Filosofia, Ciências e Letras de Ribeirão Preto da USP.

RESUMO. As transformações que vêm ocorrendo na estrutura das relações familiares, referentes aos vínculos conjugais; as novas formas e padrões de comportamento e relacionamento existentes entre os sexos, acham-se ligadas a mudanças no Estado, na sociedade e na comunidade em geral. Nos dias atuais, é dada à violência uma grande visibilidade, e tem-se consciência de que a sua presença significa um confronto direto com os Direitos da Pessoa Humana. Os objetivos dessa pesquisa foram: a) caracterizar o perfil da mulher que sofre violência física de seu companheiro e registra queixa em Delegacia de Defesa da Mulher (DDM); b) o do homem que comete violência contra sua companheira c) a agressão sofrida e como é o relacionamento do casal que vivencia a violência. Trata-se de uma pesquisa quantitativa e de cunho descritivo tendo por base análise de documentos registrados na DDM de Goiânia, nos anos de 1999 e 2000, além de processos de denúncias de violência contra a mulher no ambiente doméstico neste período. Analisou-se a violência física, incluindo Lesão Corporal e Ameaça, arts 129 e.147 do Código Penal. Verificou-se que de um ano para outro houve aumento da freqüência de denúncias, que as mulheres alegam como motivo a bebida e o ciúme do seu companheiro, que avaliam negativamente seu relacionamento. Discute-se frente a esses resultados, porque grande parte das denunciantes faz a denúncia para logo em seguida desistir da mesma, retirando sua queixa.e acaba voltando para casa e vendo sua situação de violência ser reiniciada.

PALAVRAS-CHAVE: mulher; família; violência.

ABSTRACT. Transformations are occurring in the structure of family relations, referring to matrimonial links; the new ways and patterns of behavior and relationship existing between sexes are tied to changes in the State, the society and in the community. Nowadays, violence has a great visibility and her presence is a confrontation with the Human Rights. The aim of this research was: a) to characterize the women that suffers domestic violence; b) The men that attack his women and c) The type of violence suffered and the relationship of the couple who have this situation at home. This is a descriptive, quantitative research, based on the analysis of documents registered at the DDM of Goiania, in 1999 and 2000, and the processes of domestic violence against women. It was studied the physic violence, with corporal lesions and threats. The results show the increase of denouncement from one year to the next, that the violence reasons the women perceive are the alcoholism and the husband jealousy, and that they use to evaluate negatively their relationship; what is discussed are the reasons why the majority of women few time after the denouncement, give it up and come back to their homes where the violence recommences.

KEYWORDS: woman; family; violence.

RESUMEN. Las transformaciones que viene ocurriendo en la estructura de las relaciones familiares referente a los vínculos matrimoniales, las nuevas formas y padrones de comportamiento y relacionamientos existentes entre los sexos, se encuentran relacionadas a cambios de estado, en la sociedad y en la comunidad en general, posibilitando nuevos encuentros y desdoblamientos. En los días actuales, se da a la violencia una gran visibilidad, y tenemos conciencia de que su presencia significa un conflicto directo con los Derechos de la Persona Humana. El objetivo es caracterizar el perfil de la mujer que sufre violencia física de su esposo/compañero y denunciar en la Jefatura de Defensa de la Mujer (DDM).Caracterizar el perfil del hombre que comete violencia contra su esposa/compañera. Caracterizar la agresión sufrida y como es el relacionamiento de las parejas en que la violencia se hace presente y fue denunciado en la DDM.La encuesta es cuantitativa y descriptiva teniendo como base el análisis de documentos en la DDM y constantes de denuncias de violencia contra la mujer en el ambiente doméstico.Las participantes que hicieron parte de esta encuesta fueron mujeres que efectuaron una o mas denuncia de violencia física, sufrida por su esposo/compañero en la DDM, en los años de 1999 y $2000 . L a$ violencia que interesa a nuestra encuesta es la lesión física corporal art. 129 del Código Penal (CP) y la amenaza art. 147 del CP. El interrogante frente a esos resultados es que grande parte de las denunciantes realiza la denuncia para luego en seguida desistir de la misma, retirando su queja, y acaba retornando para su casa donde la situación de violencia se reinicia.

PALABRAS-CLAVE: mujer; familia; violencia.

Recebido em: 05/08/2004

Aceito em: $02 / 12 / 2004$
Mirian Botelho Sagim

Rua Galileu Galilei, 1046 - Ap. 04 - Jardim Irajá

14020-590 - Ribeirão Preto - SP

E-mail: sagimbm@usp.br 


\section{INTRODUÇÃO}

São muitas as transformações que vêm ocorrendo na estrutura das relações familiares, no vínculo conjugal, nos padrões de comportamento e relacionamento entre os sexos; contudo, a despeito dessas mudanças permanece o problema da violência doméstica contra a mulher, tendo-se apenas, na atualidade, maior visibilidade dele. Mas, há uma necessidade de que seja investigado, tanto para se ter uma descrição acurada do que acontece quanto para melhor compreensão das variáveis a ele relacionadas.

É fato inconteste, pois, que alterações vêm se fazendo presentes na sociedade e nas relações nela existentes, contudo, estas ora têm significado avanços ora assumem a característica de retrocesso, ou se está 'marcando passo' sem conseguir encontrar formas adequadas de lidar com o problema; e, neste caso, insere-se a violência, presente desde sempre, aparecendo com maior ou menor intensidade em épocas diferentes, como um fenômeno mundial que perpassa todas as culturas, etnias, tipos de economia, regimes políticos e registrando atualmente uma freqüência elevada. A violência doméstica contra a mulher, "trata-se de um problema antigo, freqüente, que ocorre em todas as partes, seja no hemisfério sul ou no norte, mas ao qual ninguém dá a devida importância" ${ }^{1}$.

Existem muitas definições sobre violência; começando pelas do dicionário, encontram-se várias: Violência é $1^{\circ}$ qualidade de violento. $2^{\circ}$ Ato violento. $3^{\circ}$ Ato de violentar ${ }^{2}$. Ou seja, neste caso são apenas sinônimos e não chegam a esclarecer verdadeiramente o que se pode entender por violência.

Buscando, por outro lado, verificar como os pesquisadores que trabalham na área a definem, não se encontra também unanimidade.

Michaud argumenta que a violência é aquilo que as sociedades consideram como tal, variando de uma cultura e sociedade a outra, e também conforme o momento histórico vivido ${ }^{3}$. Minayo diz que a violência, em termos gerais, é um complexo e dinâmico fenômeno bio-psico-social, cujo espaço de criação e desenvolvimento é a vida em sociedade, sendo assim uma ação que não faz parte da natureza humana e que não apresenta raízes biológicas ${ }^{4}$.

Já Roja coloca que "em termos gerais, quando se fala e se pensa sobre violência se pensa no uso intencionado da força física contra um semelhante com o propósito deferir, abusar, roubar, humilhar, dominar, ultrajar, torturar, destruir ou causar morte" 5 . A extensão dessas afirmações leva a que se entenda que violência pode ser a utilização de força bruta ou instrumentos para cometer atos contra alguém, numa maneira de agir com ímpeto e intensamente, para conseguir o que se quer ou para encerrar uma discussão, tendo vencido de algum modo, impondo seu ponto de vista. Conseqüentemente, pode-se dizer que a violência é um ato de brutalidade, abuso, agressão, constrangimento e desrespeito para com qualquer pessoa.

A expressão violência contra a mulher refere-se a "qualquer violência que tem por base o gênero que resulta ou pode resultar em danos ou sofrimentos de natureza física, sexual, ou psicológica, incluindo ameaças, coerção ou privação arbitrária da liberdade, seja na vida pública ou privada." ${ }^{6}$. Na busca por unificar critérios, a ONU estabeleceu que a expressão "violência contra a mulher, se refere a todo ato de violência que tenha e que possa ter como resultado um dano como o sofrimento físico, sexual ou psicológico para a mulher, inclusive as ameaças e seus atos de coação, ou a privação arbitrária de sua liberdade, tanto que se procedam em sua vida pública ou privada ONU ?

Como já se colocou anteriormente, nos dias atuais, por um conjunto grande de fatores, é dada à violência grande visibilidade, seja porque o interesse está em denunciar, ou porque ela, de fato, encontrase exacerbada entre os mais diversos grupos sociais, ou ainda porque se mostra gratuita, mas, sobretudo pela consciência de que a sua presença significa um confronto direto com os Direitos da Pessoa, uma vez que suas conseqüências são: opressão, pânico, medo, insegurança, sensação de abandono, depressão, implicando em tortura psicológica, humilhação e perda da liberdade ${ }^{8}$. 
Quando se focaliza a violência que ocorre dentro da família, considerada 9 "um ninho de afeto, as pessoas sentem-se envergonhadas de admitir, mesmo para amigos, que um membro de sua família prática violência. Assim, qualquer que seja a modalidade de violência, geralmente se forma em torno dela uma conspiração do silêncio. Ninguém fala sobre o assunto" ${ }^{10}$.

Torna-se, pois, quase inacreditável pensar que dentro de seu lar a mulher esteja à mercê de um companheiro agressivo; isto contraria o que se poderia esperar, uma vez que este espaço é visto como sagrado. No casamento supõe-se que homens e mulheres encontrarão não só a satisfação sexual, mas também uma compreensão mútua de suas necessidades afetivas, num patamar de igualdade e troca, de direitos, deveres e cumplicidades.

Os dados da literatura mostram que é rara a mulher que se defende; mais comum é ela se calar diante da violência sofrida, encarando-a como parte do seu destino. Concorda-se, então, que ela necessita de ajuda e apoio para conseguir sair de uma relação violenta. Contudo, cada uma reage de um modo; há aquelas que mesmo não estando satisfeitas com o tipo de vida que levam, mas mal esboçam um ato de defesa e muito menos tentam reagir, ou deixam transparecer algo que estão sofrendo, por que não foram socializadas para tal, e reivindicar seria vergonhoso; outras se acostumaram a calar diante de todas as atitudes do companheiro, abafando seus desejos, sonhos, deixando que ele invada sua privacidade e tolha seus atos. Desprovidas de autoridade para se contraporem à violência sofrida, e preocupadas com o que os outros possam pensar de seu casamento, elas se conformam com a situação em que vivem; e há aquelas que, por terem uma condição financeira favorável, recorrem ao consultório do terapeuta para resolverem seus problemas $^{\star \star \star *}$.

Mas, o que pode ocorrer desde o início do casamento é bem diferente, a mulher começa a perder

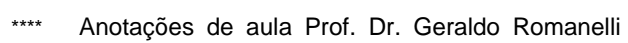

parte de sua liberdade e individualidade. Para as feministas isto principia com a mudança de seu nome, e de seu papel na sociedade, sendo chamada respeitosamente de "senhora", suas amigas terão que passar pelo crivo e aprovação de seu marido, e as mais liberais e independentes serão reprovadas, para que suas idéias não a influenciem e coloquem em risco o relacionamento; ela passa a ser responsável pela manutenção do lar com todas as suas obrigações e seu tempo é limitado. Mas, é certo que cada uma reage de uma forma, diante de um problema ou violência sofrida.

Há muitos estudos mostrando que é grande o percentual de mulheres que não estão satisfeitas com sua vida, o que não significa que se disponham a reagir e de forma drástica, alterando inteiramente sua rotina e relações. A análise dessas situações e uma presença freqüente na mídia dos problemas de violência levaram ao interesse por buscar compreender melhor esta problemática.

As pesquisas e as estatísticas acabam por estimular novos estudos, sobretudo no que diz respeito a suas causas e ao andamento dos processos de denúncia, suas motivações e possíveis variáveis relacionadas.

São muitas as questões que surgem tendo como ponto de partida os estudos realizados até agora e a alta freqüência da violência contra a mulher no ambiente doméstico, bem como a sugestão de que o fenômeno está se expandindo.

\section{OBJETIVO}

Esta pesquisa tem pois por objetivo, partir da análise de documentos constantes de processos da Delegacia de Defesa da Mulher (DDM) em que estão registradas as denúncias de violência contra ela no ambiente doméstico, verificar como a violência sofrida é interpretada pela mulher, identificando também as características dessa que faz as denúncias, bem como de seu companheiro, visando obter informações que permitam fundamentar projetos futuros de intervenção, a partir de uma 
compreensão mais ampla, e ao mesmo tempo, aprofundada do problema. Trata-se, pois de uma pesquisa de cunho descritivo, tendo como ponto inicial a visão das mulheres sobre a violência que vivenciam. Os objetivos específicos são:

1. Caracterizar o perfil da mulher que sofre violência física de seu marido/companheiro e registra queixa em DDM.

2. Caracterizar o perfil do homem que comete violência contra sua esposa/companheira.

3. Caracterizar a agressão sofrida e como é o relacionamento do casal em que a violência se faz presente e foi registrada queixa em DDM.

\section{MÉTODO}

Esta pesquisa se define como documental, quantitativa, baseada na análise do material registrado na DDM, quando da denúncia de violência sofrida pelas mulheres no ambiente doméstico, e constantes de processos.

O primeiro passo para a realização da pesquisa foi estabelecer um contato na Delegacia de Defesa da Mulher de Goiânia-Goiás, apresentando o pré-projeto para a delegada titular, e pedindo-lhe autorização (Termo de Autorização da Delegada da DDM-GO) para ter acesso aos seus arquivos, uma vez que o objetivo compreendia fazer um levantamento do que foi registrado como queixa em 1999 e $2000^{* * * *}$.

Concedida à autorização para acessar os arquivos da DDM e os processos correspondentes aos casos, avaliou-se o tipo de material que se teria à disposição, tendo-se verificado que existem 2 categorias diversas: 1- Os Boletins de Ocorrência (BOs), que têm apenas os dados iniciais de identificação do caso; 2- Os Termos Circunstanciados de Ocorrência (TCOs), criado pela lei 9099/95, do Juizado Especial Civil e Criminal, que contêm toda a declaração da vítima, a indicação do ato formal,

Todos os cuidados com os procedimentos éticos foram tomados na coleta dos dados dos sujeitos, tanto da mulher (vítima), como do homem (agressor), no sentido de não mencionar seus nomes ou qualquer outra informação capaz de levar a sua identificação. conforme o previsto no Código Penal (CP), e possuem força jurídica para gerar um processo.

Terminada esta primeira análise, foram estabelecidos critérios para a seleção do material a ser utilizado.

1. Inicialmente definiu-se que seriam separados os BOs e TCOs referentes à denúncia por mulheres de violência física (Lesão Corporal, art 129 do CP e Ameaça, art. 147 do CP) cometida contra elas por seu marido/ companheiro, restringindo-se aos anos de 1999 e 2000.

Obteve-se um total de 210 registros, para o ano de 1999, referente a Violência Física com Lesão Corporal (correspondendo a $44 \%$ do total de ocorrências registradas nesse ano na DDM GO) e mais 270 registros de Ameaça (computando 56,\% do total de ocorrências em 1999)

Para o ano de 2000 foram localizados 407 registros de Violência Física com Lesão Corporal, (representando 48\% das ocorrências registradas nesse ano na DDM.) e mais 488 registros de Ameaça (correspondendo a 52\% do total de ocorrências nesse ano na DDM).

\section{PROCEDIMENTO}

De posse dos documentos buscou-se analisar quais as informações que traziam e computá-las.

1. Fato - A primeira parte descrita do TCO era o Fato, tendo-se coletado os seguintes dados: a) Local da ocorrência: residência da vitima, residência do agressor, via pública, outros. b) Origem da denúncia: Pela própria mulher (Direta), por flagrante, pela Policia Militar, pelo Conselho Tutelar, pela mãe da vítima. c) Horário da ocorrência do fato (manhã, tarde, noite) d) Tipo de violência, segundo artigos do CP, se Lesão Corporal e/ ou Ameaça.

2. Vítima - A seguir foram computados os dados da vítima, já separando conforme fosse Lesão Corporal e/ou Ameaça: a) Estado Civil (casada, amasiada, divorciada, desquitada, 
separada). b) Cor . c) Profissão (todas as encontradas nos TCOs). d) Naturalidade (Informação sobre o Estado de origem da vítima).

3. Agressor - Na etapa seguinte foram coletados os dados do TCO, referentes ao Agressor, também já separando em Lesão corporal e/ou Ameaça: a) Cor (Branca, negra, morena, parda, não consta, clara, mulata, outras). b) Profissão (listadas todas as profissões encontradas). c) Naturalidade (Estado de origem do agressor). d) Grau de instrução (Analfabeto, primário, primário incompleto, $1^{\circ}$ grau completo, $1^{\circ}$ incompleto, $2^{\circ}$ grau incompleto, $2^{\circ}$ completo, $3^{\circ}$ grau incompleto, $3^{\circ}$ completo, não consta). e) Estado civil (casado, separado, amasiado, solteiro, concubinato, divorciado, desquitado, separado, não consta, convivente, viúvo, outros).

4. A próxima fase teve por objetivo obter as informações concernentes aos depoimentos das vítimas, encontrados no histórico da ocorrência registrada no TCO.

\section{RESULTADOS}

Terminada a fase de coleta, foi criado, para a parte quantitativa, um banco de dados, para permitir fazer as análises e possibilitar cruzamentos. E, em seguida foram elaborados sistemas de categorias (análise quantitativo-interpretativa, segundo o modelo proposto por. ${ }^{9}$ ), para os relatos obtidos através dos depoimentos, anotados no momento em que as mulheres registravam a queixa.

Os resultados quanto ao Fato mostram que: a) $\mathrm{Na}$ grande maioria das vezes é a própria mulher quem faz a denúncia de violência sofrida (82\%); b) Esta tende a ocorrer em sua própria casa $(83,8 \%)$; c) O horário mais freqüente é entre 16 e 23 horas (90\%); d) As lesões sofridas são hematomas e

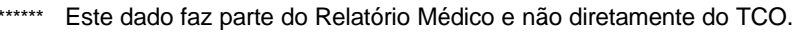

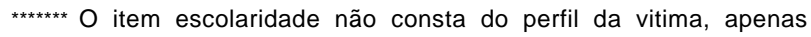
do agressor.
}

escoriações e se localizam na cabeça e membros superiores, não levam à internação, nem exigem dispensa do trabalho; e) $\mathrm{O}$ agressor tende mais frequentemente a praticar a violência usando as próprias mãos e pés.

Quanto à Caracterização das Vítimas: a) A maioria das mulheres tem uma união consensual (57\%), seguida da legal (42\%); b) $65 \%$ delas têm filhos com este parceiro; c) Cerca de $40 \%$ são do lar e $60 \%$ trabalham fora; d) Sua idade varia de 15 a 60 anos, mas a maioria é jovem (21 e 35 anos- 65\%); e) Elas são brancas. O tempo de união varia de menos de 1 a 35 anos, sendo as concentrações no período de 1 a 3 anos (38,\%) e de 4 a 7 anos (26\%), havendo uma diminuição gradativa a partir dos 7 anos.

Quanto ao Agressor: a) Ele é branco; b) A maioria está empregado, prevalecendo a profissão de pedreiro; c) Ele possui no máximo 8 anos de escolaridade; d) Sua idade varia de 16 e 80 anos.

Quanto à Percepção da mulher sobre seu relacionamento: a) Predomina a visão de que ele é ruim, marcado por desentendimentos (91\%); b) 0 agressor é visto como ignorante, implicante, grosseiro, violento, bruto e ciumento (cerca de $13 \%$ para cada característica negativa).

Os Motivos da agressão. Verificou-se, a partir da fala das vítimas, certa diversidade de motivos para as agressões que sofrem: bebida (28\%), ciúmes(14\%), não aceitação da separação(16\%), presença da amante (5\%), sem motivo (12\%), desemprego (3\%), mulher trabalhar fora(2\%), por motivo banal (3\%), sexo (4\%), nada consta no registro (12\%); contudo assinala-se que os dados obtidos indiquem que a distribuição entre eles não é eqüitativa, observando-se a predominância de 3 deles, a bebida, o ciúmes e não querer a separação.

Ao falar da bebida como motivo da agressão, as mulheres dizem frases como: 'ele bebe e me bate', 'ele só é agressivo quando bebe', 'quando não bebe ele é bom companheiro'.

A seqüência do processo - Após a denúncia, verificou-se que apenas de 2 a 5\% das mulheres decide dar continuidade ao processo, tendo-se assim 
que a grande maioria retoma seu cotidiano com o parceiro, havendo também uma porcentagem elevada de reincidências.

\section{DISCUSSÃo}

Sumarizando os dados encontrados, chama atenção o fato de predominar a união informal, mas existir também uma proporção elevada de mulheres casadas; de outro lado, a faixa etária delas é bem ampla, mas a maioria pode ser considerada como jovem. Isto leva a que se pergunte se o que acontece é que depois de algum tempo a violência cessa, ou se elas conseguem sair desse tipo de relacionamento em que impera a violência. No geral, o relacionamento com o agressor dura já alguns anos e elas tendem a ter filhos com este parceiro, ainda que sua visão dele seja negativa, bem como a do relacionamento, assinalado como ruim e destituído de prazer na convivência com o companheiro. Esses são resultados que concordam com o de outras pesquisas.

Um segundo ponto que se indaga é sobre qual o significado da violência para a mulher, dentro do contexto da família, porque, fazendo-se a relação da freqüência de denúncias com a continuidade dos processos, o que os dados mostraram é que, logo após ter comparecido à DDM, as mulheres não dão seqüência ao processo, então pode-se interpretar isto seja porque elas se arrependem, ou se sentem satisfeitas com a atitude que tomaram, esperam bons resultados e por isso retornam ao convívio, a despeito de terem relatado que seu companheiro é violento, bruto; ainda aparece como algo pouco claro o fato de se ter verificado em alguns registros que elas dizem que os agressores são bons pais, o que é contraditório também com dados de outras pesquisas que indicam alto índice de maus tratos contra crianças e adolescentes em lares em que existe violência contra a mulher.

Pode-se afirmar que a violência aparece entre adultos como uma relação de poder, de um sobre o outro, quando se quer que algo seja feito ou que deixe de sê-lo, e, nesta perspectiva a mulher seria o membro mais fraco. O que se deve questionar mais intensamente é que esta violência ocorre em lares em que existem crianças, que assistem a tudo, entendendo o que ocorre a sua maneira e principalmente tendo um modelo de relacionamento dominado pelo comportamento inadequado dos adultos. E, do ponto de vista do desenvolvimento, isto pode gerar insegurança, medo de apanhar e de abandono pela própria mãe ou pelo pai. É também em função disto que a literatura tem apontado o fato de que existe uma tendência a que a violência venha a se repetir quando esta geração mais nova formar o seu núcleo familiar.

Analisando os motivos dados pela mulher, e que se centralizam na bebida ou no ciúmes, verificase que ela se isenta de qualquer culpa ao mesmo tempo em que coloca os fatores como externos também ao que acontece dentro do lar. Interessa assinalar que o local em que os homens bebem é o bar da esquina de sua casa, com os amigos do bairro, depois do trabalho, e este parece ser um espaço em que se sentem tranqüilos para discutir todos os assuntos, e até sobre sua companheira; dir-se-ia que eles "enchem a cabeça uns dos outros", dando margem a que as insatisfações do seu cotidiano ganhem força e se dirijam a quem os espera em casa, sendo que aí qualquer motivo é suficiente para desencadear os atos de violência.

Esta relação conflituosa tem também outros condicionantes como o ciúme, que aparece acentuadamente nos depoimentos, conjuntamente com o homem, agressor, não querendo de forma alguma a separação. Qual é para a mulher o significado de ele ter muito ciúme, não aceitar a separação, mas ser violento? Será que ela se sente valorizada nessa situação, vê-se como 'indispensável na vida dele', e que esse ciúme exacerbado, que acaba em violência, é no pensar dela, o medo que seu companheiro tem de perdê-la? Nesse caso, ela se veria como poderosa, valorizada porque ele não a deixa sair da vida dele.

As mulheres que não trabalham e são do lar, muitas vezes não tem para onde ir, caso venham a se separar, mas a grande maioria da amostra desse estudo tem trabalho e como se sustentar; razoa porque este não pode ser o motivo alegado para retirar a denúncia. Trata-se, pois de buscar identificar 
quais as reais razões para que as separações nos casos de violência doméstica atuais não se consumem.

É uma relação complicada, conflituosa, que a mulher se sente usada, mas ao mesmo tempo se considera indispensável e importante na vida desse homem, que para conseguir o que quer, bate, agride e ameaça.

O problema maior é que essa situação de violência atinge não só à mulher, porque como acontece diante dos filhos, pode sim prejudicar e muito a eles; torna-se então necessário, utilizar esses resultados para pensar em projetos de intervenção que possam atingir tanto aos adultos quanto à geração mais nova, buscando trabalhar para promover a saúde da família e um desenvolvimento de todos seus membros, construindo uma qualidade de vida capaz de favorecer padrões comportamentais que tornem o relacionamento entre todos os membros uma fonte de afeto e segurança.

\section{REFERÊNCIAS}

1 Teles MAA, Melo M. O que é violência contra a mulher. São Paulo: Brasiliense; 2002.

2 Ferreira $\mathrm{ABH}$. Mini Dicionário Aurélio. Rio de Janeiro: Nova Fronteira;1993.
3 Michaud YA. Violência. São Paulo: Ática; 1998.

4 Minayo MCS. A Violência social sob a perspectiva da saúde pública. Cad Saúde Pública 1994; 10(Supl 1): 07-18.

5 Rojas L. Las semilhas de la violência .Espasa hoy. Madri. Violência domestica em América Latina y el Caribe. Washington: Banco Interamericano de Desarrollo; 1997.

6 Conselho do Direito da Mulher. Você sabia que os direitos da mulher também são direitos humanos? Brasília: Governo do Distrito Federal.1999.

7 Organização das Nações Unidas. Declaracion sobre la eliminacion de violência contra la mujer. Documento Oficial de la Asamblea General; supl: 38 A/47/38, secc I, p.3-7.1993

8 Schraiber LB, D' Oliveira AFLP. Violência contra mulheres: Interfaces com a saúde. Comunicação, Saúde, Educação 1999; 3(5).

9 Biasoli-Alves ZMM. A pesquisa em psicologia - análise de métodos e estratégias na construção de um conhecimento que se pretende cientifico. In: Romanelli G, Biasoli- Alves ZMM, organizadores. Diálogos metodológicos sobre prática de pesquisa. Ribeirão Preto: Legis-Summa;1998. p.35-157.

10 Saffioti, H.I.B.Violência Doméstica ou a lógica do galinheiro.Violência em Debate. São Paulo: Ed Moderna; 1997. p.39-57. 